\title{
Mitochondria-targeted triphenylphosphonium-based compounds do not affect estrogen receptor $\alpha$
}

\author{
Ludmila A Zinovkina ${ }^{1,2}$, Alina K Galivondzhyan ${ }^{1}$, Anastasia S Prikhodko ${ }^{2,3}$, Ivan I Galkin ${ }^{3}$, Roman A Zinovkin ${ }^{\text {Corresp. }}$ \\ $2,3,4$ \\ 1 Faculty of Bioengineering and Bioinformatics, Lomonosov Moscow State University, Moscow, Russia \\ 2 Institute of Mitoengineering, Moscow State University, Moscow, Russia \\ 3 Belozersky Institute of Physico-Chemical Biology, Lomonosov Moscow State University, Moscow, Russia \\ 4 Institute of Molecular Medicine, Sechenov First Moscow State Medical University, Moscow, Russia \\ Corresponding Author: Roman A Zinovkin \\ Email address: roman.zinovkin@gmail.com
}

Background: Targeting negatively charged mitochondria is often achieved using triphenylphosphonium (TPP) cations. These cationic vehicles may possess biological activity, and a docking study indicates that TPP-moieties may act as modulators of signaling through the estrogen receptor $\alpha$ (ER $\alpha$ ). Moreover, in vivo and in vitro experiments revealed the estrogen-like effects of TPP-based compounds. Here, we tested the hypothesis that TPP-based compounds regulate the activity of ER $\alpha$.

Methods: We used ERa-positive and ER $\alpha$-negative human breast adenocarcinoma cell lines (MCF-7 and MDA-MB-231, respectively). Cell proliferation was measured using a resazurin cell growth assay and a real-time cell analyzer assay. Cell cycle progression was analyzed using flow cytometry. Real-time PCR was used to measure transcription driven by estrogen-responsive promoters in cells transfected with an estrogen response element (ERE) $)_{3}$-luciferase expression vector.

Results: The TPP-based molecules SkQ1 and $\mathrm{C}_{12}$ TPP, as well as the rhodamine-based SkQR1, did not increase the proliferation or alter the cell cycle progression of MCF-7 cells. In contrast, $17 \beta$ estradiol increased the proliferation of MCF-7 cells and the proportion of cells in the S/G2/M-phases of the cell cycle. TPP-based compounds did not affect the induction of transcription of an ERE-luciferase expression vector in vitro, and SkQ1 did not alter the levels of expression of estrogen-dependent genes encoding GREB1, TFF1, COX6, and IGFBP4.

Conclusion: TPP-based compounds do not possess properties typical of ER $\alpha$ agonists. 
1 Mitochondria-targeted triphenylphosphonium-based

2 compounds do not affect estrogen receptor $\alpha$

3

4

Ludmila A. Zinovkina ${ }^{1,2}$, Alina K. Galivondzhyan ${ }^{1}$, Anastasia S. Prikhodko ${ }^{2,3}$, Ivan I. Galkin ${ }^{3}$, Roman A. Zinovkin 2,3,4.

${ }^{1}$ Faculty of Bioengineering and Bioinformatics, Lomonosov Moscow State University, 119991 Moscow, Russia;

${ }^{2}$ Institute of Mitoengineering, Moscow State University, 119991 Moscow, Russia;

${ }^{3}$ Belozersky Institute of Physico-Chemical Biology, Lomonosov Moscow State University, 119991 Moscow, Russia;

${ }^{4}$ Institute of Molecular Medicine, Sechenov First Moscow State Medical University, 119991 Moscow, Russia.

Corresponding Author:

Roman A. Zinovkin

Leninskie Gori 1-40, Moscow, 119991, Russia

Email address: roman.zinovkin@gmail.com

\section{Abstract}

Background: Targeting negatively charged mitochondria is often achieved using triphenylphosphonium (TPP) cations. These cationic vehicles may possess biological activity, and a docking study indicates that TPP-moieties may act as modulators of signaling through the estrogen receptor $\alpha(\mathrm{ER} \alpha)$. Moreover, in vivo and in vitro experiments revealed the estrogen-like effects of TPP-based compounds. Here, we tested the hypothesis that TPP-based compounds regulate the activity of $E R \alpha$.

Methods: We used ER $\alpha$-positive and ER $\alpha$-negative human breast adenocarcinoma cell lines (MCF-7 and MDA-MB-231, respectively). Cell proliferation was measured using a resazurin cell growth assay and a real-time cell analyzer assay. Cell cycle progression was analyzed using flow cytometry. Real-time PCR was used to measure transcription driven by estrogen-responsive promoters in cells transfected with an estrogen response element (ERE) ${ }_{3}$-luciferase expression vector.

Results: The TPP-based molecules SkQ1 and $\mathrm{C}_{12} \mathrm{TPP}$, as well as the rhodamine-based SkQR1, did not increase the proliferation or alter the cell cycle progression of MCF-7 cells. In contrast, $17 \beta$ estradiol increased the proliferation of MCF-7 cells and the proportion of cells in the S/G2/M-phases of the cell cycle. TPP-based compounds did not affect the induction of transcription of an ERE-luciferase expression vector in vitro, and SkQ1 did not alter the levels of expression of estrogen-dependent genes encoding GREB1, TFF1, COX6, and IGFBP4. 
40 Conclusion: TPP-based compounds do not possess properties typical of ER $\alpha$ agonists.

41

\section{Introduction} et al., 2012). 2014).

Mitochondria are important target for drug development (Zielonka et al., 2017). Mitochondriatargeted molecules include drug candidates, intracellular probes and sensors (Zinovkin \& Zamyatnin, 2019). The drug of interest is usually linked via a carbon linker to the triphenylphosphonium (TPP) cation. The latter effectively confers mitochondria-targeting activity. Lipophilic TPP-based molecules are readily transported across the membranes of cells and mitochondria, and cationic TPP ensures targeting to negatively charged mitochondria through electrostatic attraction. The widely used mitochondria-targeted antioxidants MitoQ and SkQ1 exploit the TPP cation as a vehicle. Despite a wealth of experimental data obtained using TPP-based compounds, numerous molecular features of intracellular signaling induced by TPPbased moieties are unknown.

The TPP cation may possess biological activity. For example, the results of a docking study suggest that TPP-moieties may act as modulators of estrogen receptor $\alpha(E R \alpha)$ (Salisbury \& Williams, 2009). Estrogens are implicated in numerous physiological functions of females and males. The major female sex hormone $17 \beta$ estradiol (E2) contributes to human development and reproduction. ERs include $\mathrm{ER} \alpha, \mathrm{ER} \beta$, and $\mathrm{G}$ protein-coupled estrogen receptor alpha. Multiple isoforms of $E R \alpha$ and $E R \beta$ function as transcription factors. ERs dimerize upon binding to E2, and the complex translocates to the nucleus where it regulates the expression of estrogendependent genes. Furthermore, indirect mechanisms operate through multiple co-regulatory proteins (Yasar et al., 2017).

Indirect evidence supports the possibility that the TPP-based antioxidants MitoQ and SkQ1 act through estrogen-like action as follows:

- The mitochondria of MCF-7 and endothelial cells contain functional high-affinity ERs (Pedram et al., 2006). Activation of these receptors by E2 inhibits UV radiation-induced cytochrome $\mathrm{C}$ release, decreased mitochondrial membrane potential, and apoptosis via the formation of mitochondrial reactive oxygen species (mROS) (Pedram et al., 2006). MitoQ exhibits the same activities. Moreover, MitoQ and SkQ1 inhibit mROS generation to prevent subsequent apoptosis (Feniouk \& Skulachev, 2017), suggesting they directly interact with mitochondrial ERs.

- Estrogen-like activity of SkQ1 is detected in female outbred SHR mice, and long-term oral administration of SkQ1 inhibits the age-related decline of the estrous function (Anisimov et al., 2008).

- SkQ1 consumption by female rats prolongs proestrus duration, typical of E2 (Chistyakov

- $\quad \mathrm{ER} \alpha$ regulates multiple $\mathrm{NF}-\kappa \mathrm{B}$ pathway components to control inflammatory responses (Kovats, 2015), and SkQ1 regulates NF- $\kappa$ B activity in endothelial cells (Zinovkin et al., 
79

80

81

82

83

84

85

86

87

88

89

90

91

92

93

\section{4}

95

96

97

98

99

100

101

102

103

104

105

106

107

108

109

110

111

112

113

114

115

116

117

- $\quad$ E2 (Brotfain et al., 2016), MitoQ (Zhou et al., 2018), and SkQ1 (Silachev et al., 2015) exert neuroprotective effects in a model of traumatic brain injury.

Experimental and clinical evidence link sustained exposure to estrogens with increased risk of developing breast cancer (Russo \& Russo, 2006). Certain mitochondria-targeted antioxidants are the subject of clinical trials (Zinovkin \& Zamyatnin, 2019). Eye drops containing SkQ1 are used to cure dry eye syndrome (Visomitin) and MitoQ is freely available as an antioxidant supplement.

TPP-based mitochondria-targeted compounds may possess estrogen-like activities, and it is critically important to investigate this possibility. Here we tested the hypothesis that TPP-based compounds such as SkQ1 regulate the activity of ER $\alpha$. For this purpose, we tested the TPPbased compounds $\mathrm{C}_{12} \mathrm{TPP}$ and SkQ1 (plastoquinone conjugated to $\mathrm{C}_{12} \mathrm{TPP}$ ). The mitochondriatargeted antioxidant SkQR1, which lacks the TPP moiety, served as a negative control. The structures of these cations are shown in Figure 1.

\section{Materials \& Methods}

Reagents

E2 and its inhibitor were 17ß-Estradiol (E2758; Sigma) and fulvestrant (I4409; Sigma), respectively. The protonophore was 2,4-dinitrophenol (DNP; D198501; Sigma). The cell culture reagents included phenol-red-free DMEM media (Paneco, Russia); charcoal-stripped fetal bovine serum (FBS; F6765; Sigma); FBS (SV30160.03; HyClone) and DMEM medium (Gibco). AlamarBlue reagent (DAL1025) was purchased from Biosource, and propidium iodide (PI) was purchased from MP Biomedicals, France. SkQ1, SkQR1, and $\mathrm{C}_{12}$ TPP were synthesized as bromide salts at the Belozersky Institute of Physico-Chemical Biology.

\section{Cell culture}

The human breast adenocarcinoma cell lines (ER $\alpha$-positive MCF-7 and ER-, progesterone receptor-, and erb-b2 receptor tyrosine kinase 2-negative [triple-negative] MDA-MB-231) were obtained from the Russian Collection of Cell Cultures (Institute of Cytology, St Petersburg, Russia). Cells were maintained in DMEM with $10 \% \mathrm{FBS}$ at $37^{\circ} \mathrm{C}$ in an atmosphere containing $5 \% \mathrm{CO}_{2}$. The media was replaced at least 6 days before an experiment, with phenol-red-free DMEM with 5\% charcoal stripped FBS to exclude activation of ERs by phenol red and serum components. The images of MCF-7 cells treated with test compounds were acquired by phasecontrast microscopy using Axioplan (Zeiss) microscope.

\section{Resazurin cell growth assay}

Cells (approximately 5,000 cells per well) were added to the wells of 96-well plates. After 2 days, the medium was replaced with fresh medium with or without the test compound. After 48 $\mathrm{h}$, cell viability was determined using a resazurin assay with AlamarBlue reagent $(2.75 \mathrm{mM})$. 
118 Fluorescence was measured after $3.5 \mathrm{~h}$ at 544/590 nm. Each experiment was repeated five or six 119 times.

120

121

Real-time cell analyzer (RTCA) assay

122 The xCELLigence system (Roche Applied Sciences, Basel, Switzerland) was used to evaluate 123 cell growth rate and viability. The system calculates a Cell Index (CI) value defined as (Rn-Rb)/

124

125

126

127

128

129

130

131

132

133

134

135

136

137

138

139

140

141

142

143

144

145

146

147

148

149

150

151

152

153

154

155

156

157 $\mathrm{Rb}$, where $\mathrm{Rn}$ is the impedance in the well at time $n$, and $\mathrm{Rb}$ is the background impedance. The cells $(20,000$ cells/well) were cultured in E-plates for $24 \mathrm{~h}$, and the medium was replaced with fresh medium supplemented with $10 \mathrm{nM}$ E2, $20 \mathrm{nM}$ SkQ1, $20 \mathrm{nM} \mathrm{C}_{12}$ TPP or $20 \mathrm{nM}$ SkQR1. For the first $2 \mathrm{~h}$, CI values were determined every $5 \mathrm{~min}$, and thereafter at $15 \mathrm{~min}$ intervals.

\section{Cell cycle analysis}

PI was used to analyze the cell cycle distribution (Galkin et al., 2014). Briefly, cells (200,000 cells per well) were added to the wells of 6 -well plates, incubated for $24 \mathrm{~h}$ and then for $48 \mathrm{~h}$ with the test compounds or controls, harvested using free-EDTA trypsin, washed with PBS, and fixed in cold $70 \%$ ethanol overnight at $4{ }^{\circ} \mathrm{C}$. The cells were subsequently stained with PI containing RNAse A and the samples were analyzed using a flow cytometer (Beckman Coulter FC500).

\section{Transfection and luciferase reporter assay.}

The estrogen-responsive element (ERE) ${ }_{3}$-Luc reporter construct (Hall \& McDonnell, 1999) containing three copies of the vitellogenin ERE was purchased from Addgene (plasmid no. 11354). The plasmid was purified using a Plasmid midi kit (QIAGEN, USA). Cells were grown to $80 \%-90 \%$ confluence and transiently transfected with TransIT-LT1 Transfection Reagent (Mirus Bio, USA). Firefly luciferase activity was measured using a Luciferase Assay System (Promega, USA), and luminescence was measured using a LKB 1251 Luminometer.

Luminescence was normalized to the total protein content measured using the Bradford assay.

RNA purification and real-time PCR.

Total RNA was purified from MCF-7 cells using a Quick-RNA MiniPrep Kit according to the manufacturer's protocol (Zymo Research, USA). Purified RNA was reverse transcribed using SuperScript III reverse transcriptase (Thermo Fisher, USA) and used for real-time PCR performed using an iCycler iQ amplifier (Bio-Rad, USA) with EVA Green Master Mix (Syntol, Russia) according to the manufacturer's instructions. Primer sequences are listed in Table S1. The efficiencies of the primers were within $88 \%-100 \%$. The relative expression levels of the target genes was determined using the $\Delta \Delta \mathrm{Ct}$ method with the calculated primer efficiencies. RPL32 mRNA encoding ribosomal protein L32 served as a reference.

\section{Statistical analysis}

Data were analyzed using the one-way ANOVA with post-hoc Tukey HSD, or with an unpaired Student's $t$-test. $\mathrm{P}<0.05$ was considered to indicate a significant difference. 
158

159

160

161

162

163

164

165

166

167

168

169

170

171

172

173

174

175

176

177

178

179

180

181

182

183

184

185

186

187

188

189

190

191

192

193

194

195

196

197

\section{Results}

Effect of TPP-based compounds on the growth of an estrogen-dependent human breast cancer cell line.

We measured cell proliferation in the presence of 0.2 to $20 \mathrm{nM} \mathrm{C}_{12}$ TPP and SkQ1. SkQR1 served as a negative control (Fig. 1). Higher concentrations (e.g., $\geq 200 \mathrm{nM}$ ) significantly inhibited cell growth (Supplementary Fig. 1). E2 $(10 \mathrm{nM})$ served as a positive control, and fulvestrant (10 nM) served as an ER $\alpha$ antagonist. ER-positive MCF-7 cells were incubated for $48 \mathrm{~h}$ with the test compounds with or without fulvestrant, and cell growth was measured using the resazurin test. Treatment of MCF-7 cells with $10 \mathrm{nM}$ E2 significantly ( $p<0.02$ [ANOVA]) enhanced cell proliferation (Fig. 2). The TPP-based compounds and SkQR1 did not significantly affect cell proliferation. However, $20 \mathrm{nM} \mathrm{SkQ1,} 0.2 \mathrm{nM} \mathrm{C}_{12} \mathrm{TPP}, 20 \mathrm{nM} \mathrm{C}_{12} \mathrm{TPP}$ and $20 \mathrm{nM}$ SkQR1 increased resazurin fluorescence by approximately $10 \%$ compared with untreated cells (Fig. 2). This increase was not significant and concentration-independent. Fulvestrant significantly $(\mathrm{p}<0.04$ [ANOVA] ) lowered resazurin fluorescence in cells treated with $10 \mathrm{nM} \mathrm{E2}$, and the fluorescence of most samples decreased, although the differences were not significant.

The same experiments employing ER $\alpha$-negative MDA-MB-231 cells did not reveal a significant effect of $\mathrm{E} 2$ or the test compounds (Fig. 3). However, resazurin fluorescence increased after treatment with $2 \mathrm{nM} \mathrm{SkQ1,} 20 \mathrm{nM} \mathrm{SkQ1,} 20 \mathrm{nM} \mathrm{C}_{12}$ TPP, or $20 \mathrm{nM} \mathrm{SkQR1}$ but not with E2 (Fig. 3). These data suggest that resazurin fluorescence may not correlate with the number of cells but with a slight change in mitochondrial metabolic activities potentially induced by TPP cations. In agreement with this supposition, resazurin fluorescence was slightly enhanced by the mitochondrial protonophore 2,4-dinitrophenol (12 $\mu \mathrm{M}$ DNP) when added to MCF-7 or MDAMB-231 cells (Fig. 2C, 3C). We concluded therefore that the resazurin assay is inapplicable to the estimation of cell proliferation in the presence of mitochondria-targeted compounds. Thus, other assays are required to unambiguously measure the effect of the TPP-based compound on cell proliferation.

The potential of TPP-based compounds to affect the proliferation of ER-positive MCF-7 cells was tested using an RTCA assay (Fig. 4). The test compounds, except E2, did not significantly affect the CI value. $\mathrm{E} 2$ first increased the $\mathrm{CI}$ value of MCF-7 cells approximately $36 \mathrm{~h}$ after its addition.

Effect of TPP-based compounds on the cell cycle distribution of estrogen-dependent breast cancer cells.

Cell proliferation is characterized by increases in the numbers of cells in the S, G2, and M phases. To determine the distribution of cells among these phases, we performed flow cytometric analysis of MCF-7 cells treated for $48 \mathrm{~h}$ with the test compounds and then with PI. E2 treatment increased the numbers of cells in the S, G2, and M phases (Fig. 5) There were no detectable changes in cell cycle distribution after treatment of the MCF-7 cells with $20 \mathrm{nM} \mathrm{SkQ1,} 20 \mathrm{nM}$ $\mathrm{C}_{12} \mathrm{TPP}$, and $20 \mathrm{nM} \mathrm{SkQR1} \mathrm{(Fig.} \mathrm{5).}$ 
198

199

200

201

202

203

204

205

206

207

208

209

210

211

212

213

214

215

216

217

218

219

220

221

222

223

224

225

226

227

228

229

230

231

232

233

234

235

236

237

Effect of TPP-based compounds on the transcription driven by an estrogen-responsive promoter Direct binding of an agonist to ER $\alpha$ activates ERE-dependent transcription. To assess the effect of TPP-based cations on ERE-dependent transcription, we transfected MCF-7 cells with the luciferase reporter construct $E_{2} E_{3}-L u c$, followed by incubation for $24 \mathrm{~h}$ with the test compounds. Only E2 increased ERE-dependent transcription and corresponding luciferaseinduced luminescence (approximately 5-fold, $\mathrm{p}=0.04$ [Student's $t$-test]; Fig. 6). The E2 antagonist fulvestrant partially inhibited this effect $(\mathrm{p}=0.21$ [Student's $t$-test]). Treatment of the transfected cells with $20 \mathrm{nM}$ SkQ1, $20 \mathrm{nM} \mathrm{C}_{12}$ TPP, and $20 \mathrm{nM}$ SkQR1 revealed no significant change in luminescence (Fig.6).

To further evaluate the possible effect of SkQ1 on the transcriptional activity of the estrogenresponsive promoters, we measured the expression in MCF-7 cells of E2 target genes encoding the following proteins: trefoil factor 1 (TFF1); growth regulating estrogen receptor binding 1 (GREB1); cytochrome c oxidase subunit VI (COX6); insulin-like growth factor binding protein 4 (IGFBP4). These genes were chosen using available mRNA expression data for MCF-7 cells treated with E2 (Yamaga et al., 2013) and relative mRNA expression was estimated using realtime PCR.

E2 treatment of MCF-7 cells increased the levels of the transcripts of all target genes (Fig. 7). The simultaneous addition of the estrogen antagonist fulvestrant with E2 partially prevented the increase in the expression of TFF1 and GREB1. Interestingly, the same effect of fulvestrant on the expressions of TFF1 and GREB 1 was observed in vehicle and SkQ1-treated samples, indicating the presence of a small amount of estrogen mimetics in the culture medium.

Treatment with any concentration of SkQ1 did not significantly influence the mRNA levels of all E2 target genes. Nevertheless, in some experiments $0.2 \mathrm{nM}$ and $20 \mathrm{nM}$ SkQ1 increased IGFBP4 expression ( $\mathrm{p}=0.047$ and $\mathrm{p}=0.13$, respectively [Student's $t$-test]). However, IGFBP4 expression was not decreased in E2-treated cells treated with fulvestrant, and IGFBP4 mRNA levels therefore cannot be considered to reliably indicate signaling downstream ER $\alpha$.

\section{Discussion}

Testing the effects of any compound on the proliferation of ER $\alpha$-positive cells is commonly employed to evaluate estrogenic properties. There are several methods available to measure cell proliferation rates. The most popular methods, the MTT assay and the resazurin test, rely on the measurement of activity of mitochondrial enzymes. The resazurin assay measures the activity of mitochondrial dehydrogenases, which convert the nonfluorescent dye resazurin to the stronglyfluorescent dye resorufin. However, the mitochondrial function greatly affects the NAD(P)Hbased viability assays, including the resazurin test (Aleshin et al., 2015). Mitochondrial uncoupling, in particular, leads to the overestimation of the MTT test results (Maioli et al., 2009). Moreover, numerous penetrating cations such as SkQ1, $\mathrm{C}_{12} \mathrm{TPP}$, and SkQR1 induce mitochondrial uncoupling mediated by free fatty acids (Severin et al., 2010; Antonenko et al., 2011). In an agreement with these data, we observed a moderate statistically insignificant

Peer) reviewing PDF | (2019:11:42851:1:3:NEW 25 Feb 2020) 
238 increase in the resazurin fluorescence in MCF-7 cells treated with the mitochondrial penetrating 239 cations or with the "classical" protonophore DNP (Fig. 2C; Fig.3C).

240 We found it interesting that the test compounds induced slightly higher resazurin fluorescence in 241 MCF-7 than in triple-negative MDA-MB-231 cells (Figs. 2 and 3). We speculate that the 242 uncoupling of oxidative phosphorylation in mitochondria and corresponding activity of 243 mitochondrial dehydrogenases may differ between these cell lines because the basal oxygen

244

245

246

247

248

249

250

251

252

253

254

255

256

257

258

259

260

261

262

263

264

265

266

267

268

269

270

271

272

273

274

275

276

277 consumption rate and proton leakage significantly differs between these cells (Radde et al., 2016). Generally, the MTT and resazurin tests are suitable for the compounds that do not influence mitochondrial function. Therefore, these tests cannot be applied to the study of TPPbased cations with mitochondrial uncoupling activities. We therefore used the RTCA assay to measure the effects of TPP-based compounds on the proliferation of MCF-7 cells. We found that these compounds did not significantly influence the CI value, which is directly proportional to the quantity, size, and attachment forces of the cell (Fig.4). Further, microscopic examination did not reveal morphological changes induced by E2 or the test compounds (Supplementary Fig. 2). Moreover, the CI value is proportional to the cell number measured using the RTCA assay, and TPP cations therefore did not significantly influence the proliferation of MCF-7 cells. Furthermore, we did not observe a detectable effect of TPP-based compounds on cell cycle distribution (Fig. 5), showing that TPP cations did not enhance the proliferation of ER $\alpha$-positive MCF-7 cells.

Despite the absence of detectable stimulatory effects of TPP on the proliferation of MCF-7 cells, we cannot exclude the direct binding of TPP to ER $\alpha$ induces downstream signaling that regulates ERE-dependent gene expression. Specifically, we found no detectable effect of TPP cations on the luciferase activity of MCF-7 cells transfected with the ERE 3 -luciferase reporter (Fig.6). However, the structures of the promoter regions of ERE-dependent genes is much more complex than the three ERE of the reporter. Further, E2 may indirectly modulate gene expression via the interaction of ER with transcription factors such as NF-kB, AP-1, and Sp-1, which, in turn, bind their cognate DNA regulatory elements (Marino, Galluzzo \& Ascenzi, 2006). We therefore tested SkQ1 as a representative TPP-based compound for its ability to regulate the expression of the ER-dependent genes GREB1, TFF1, COX6, and IGFBP4. We found that SkQ1, at any concentration tested, did not significantly upregulate the expression of these genes (Fig.7). Nevertheless, the expression of IGFBP4 mRNA varied, and the effect of SkQ1 on its expression requires further investigation. Our present data therefore lead us to conclude that SkQ1 did not directly affect $\mathrm{ER} \alpha$ and its associated downstream signaling activity related to the expression of ER-dependent genes.

In agreement with this conclusion, several lines of evidence, described below, indicate that TPPbased compounds do not possess proestrogenic effects:

- SkQ1 enhances human neutrophils apoptosis (Andreev-Andrievskiy et al., 2016; Vorobjeva et al., 2017), and E2 has the opposite effect (Molloy et al., 2003).

- Though global gene expression data for TPP-based compounds are scarce, available data on oral administration of MitoQ to wild-type mice indicate that MitoQ treatment does not 
278

279

280

281

282

283

284

285

286

287

288

289

290

291

292

293

294

295

296

297

298

299

300

301

302

303

304

305

306

307

308

309

310

311

312

313

314

315

316

317

affect a specific process or signaling pathway mediated by sex hormones (RodriguezCuenca et al., 2010).

- In mouse and rat strains, estrogen increases the incidence of tumorigenesis in several organs (Vollmer, 2003). In three mouse strains studied, prolonged SkQ1 treatment does not affect spontaneous carcinogenesis (Yurova et al., 2011). Moreover, SkQ1 does not increase the development of spontaneous tumors in BALB/c mice (Manskikh et al., 2014).

Theoretically, mitochondria-targeted compounds may possess estrogen-like activities that are not due to TPP cation. For example, certain plant quinones are phytoestrogens (Davis, 2002), and plastoquinone and ubiquinone are essential components of SkQ1 and MitoQ antioxidants, respectively. There are no reports, to our knowledge, about the ER-related activities of these quinones or the rhodamine 19 moiety of SkQR1. Our data further confirm the absence of estrogen-like activities of plastoquinone and the quinone of rhodamine 19.

The present study has the following limitations: first, we did not investigate the direct binding of the compounds to ER $\alpha$. However, our data strongly suggest low or no binding of the test compounds to ER $\alpha$. Second, we only used cell lines derived from breast cancers. Thus, the corresponding primary cells may react in a different way. Third, we cannot exclude the possibility that in vivo environmental conditions may greatly differ from the in vitro experimental conditions used here. Hypothetical coregulatory factors in tissues and organs may be involved in indirect estrogen-dependent signaling pathways together with TPP cations. Thus, indirect involvement of TPP-based compounds in estrogen signaling cannot be fully excluded.

\section{Conclusions}

For the first time, to our knowledge, we show here that TPP-based cations do not possess

properties of typical ER $\alpha$ agonists. Our finding therefore opens new possibilities for safe use of TPP-based compounds in preclinical and clinical applications.

\section{References}

Aleshin VA, Artiukhov AV, Oppermann H, Kazantsev AV, Lukashev NV, Bunik VI. 2015. Mitochondrial Impairment May Increase Cellular NAD(P)H: Resazurin Oxidoreductase Activity, Perturbing the NAD(P)H-Based Viability Assays. Cells 4:427-451. DOI: 10.3390/cells4030427. Andreev-Andrievskiy AA, Kolosova NG, Stefanova NA, Lovat MV, Egorov MV, Manskikh VN, Zinovkin RA, Galkin II, Prikhodko AS, Skulachev MV, Lukashev AN. 2016. Efficacy of Mitochondrial Antioxidant Plastoquinonyl-decyl-triphenylphosphonium Bromide (SkQ1) in the Rat Model of Autoimmune Arthritis. Oxidative medicine and cellular longevity

2016:8703645. DOI: 10.1155/2016/8703645.

Anisimov VN, Bakeeva LE, Egormin PA, Filenko OF, Isakova EF, Manskikh VN, Mikhelson VM, Panteleeva AA, Pasyukova EG, Pilipenko DI, Piskunova TS, Popovich IG, Roshchina NV, Rybina OY, Saprunova VB, Samoylova TA, Semenchenko AV, Skulachev MV, Spivak IM, Tsybul'ko EA, Tyndyk ML, Vyssokikh MY, Yurova MN, Zabezhinsky 
318 MA, Skulachev VP. 2008. Mitochondria-targeted plastoquinone derivatives as tools to interrupt 319 execution of the aging program. 5. SkQ1 prolongs lifespan and prevents development of traits of 320 senescence. Biochemistry 73:1329-1342. DOI: 10.1134/S0006297908120055.

321 Antonenko YN, Avetisyan AV, Cherepanov DA, Knorre DA, Korshunova GA, Markova 322 OV, Ojovan SM, Perevoshchikova IV, Pustovidko AV, Rokitskaya TI, Severina II, 323 Simonyan RA, Smirnova EA, Sobko AA, Sumbatyan NV, Severin FF, Skulachev VP. 2011. 324 Derivatives of rhodamine 19 as mild mitochondria-targeted cationic uncouplers. The Journal of 325 biological chemistry 286:17831-17840. DOI: 10.1074/jbc.M110.212837.

326

327

328

329

330

331

332

333

334

335

336

337

338

339

340

341

342

343

344

345

346

347

348

349

350

351

352

353

354

355

356

357

Brotfain E, Gruenbaum SE, Boyko M, Kutz R, Zlotnik A, Klein M. 2016. Neuroprotection by Estrogen and Progesterone in Traumatic Brain Injury and Spinal Cord Injury. Current neuropharmacology 14:641-653.

Chistyakov VA, Dem'yanenko SV, Alexandrova AA, Gutnikova LV, Prokof'ev VN, Kosheleva ON. 2012. Effect of plastoquinone derivative 10-(6'-Plastoquinonyl) decyltriphenylphosphonium (SkQ1) on estrous cycle and 17 $\beta$-estradiol level in rats. Biochemistry 77:1382-1386. DOI: 10.1134/S0006297912120061.

Davis SR. 2002. Phytoestrogens in the Context of SERMs. In: Manni A, Verderame MF eds. Selective Estrogen Receptor Modulators: Research and Clinical Applications. Totowa, NJ: Humana Press, 345-363. DOI: 10.1007/978-1-59259-157-2_20.

Feniouk BA, Skulachev VP. 2017. Cellular and Molecular Mechanisms of Action of Mitochondria-Targeted Antioxidants. Current aging science 10:41-48.

Galkin II, Pletjushkina OY, Zinovkin RA, Zakharova VV, Birjukov IS, Chernyak BV, Popova EN. 2014. Mitochondria-targeted antioxidants prevent TNF $\alpha$-induced endothelial cell damage. Biochemistry. Biokhimiia 79:124-130. DOI: 10.1134/S0006297914020059.

Hall JM, McDonnell DP. 1999. The Estrogen Receptor $\alpha$-Isoform (ER $\alpha)$ of the Human Estrogen Receptor Modulates ER $\alpha$ Transcriptional Activity and Is a Key Regulator of the Cellular Response to Estrogens and Antiestrogens1. Endocrinology 140:5566-5578. DOI: 10.1210/endo.140.12.7179.

Kovats S. 2015. Estrogen receptors regulate innate immune cells and signaling pathways. Cellular immunology 294:63-69. DOI: 10.1016/j.cellimm.2015.01.018.

Maioli E, Torricelli C, Fortino V, Carlucci F, Tommassini V, Pacini A. 2009. Critical appraisal of the MTT assay in the presence of rottlerin and uncouplers. Biological procedures online 11:227-240. DOI: 10.1007/s12575-009-9020-1.

Manskikh VN, Krasilshchikova MS, Vygodin VA, Egorov MV. 2014. Effect of the mitochondria-targeted antioxidant SkQ1 on development of spontaneous tumors in BALB/c mice. Biochemistry. Biokhimiia 79:1136-1139. DOI: 10.1134/S0006297914100162.

Marino M, Galluzzo P, Ascenzi P. 2006. Estrogen signaling multiple pathways to impact gene transcription. Current genomics 7:497-508.

Molloy EJ, O’Neill AJ, Grantham JJ, Sheridan-Pereira M, Fitzpatrick JM, Webb DW, Watson RWG. 2003. Sex-specific alterations in neutrophil apoptosis: the role of estradiol and progesterone. Blood 102:2653-2659. DOI: 10.1182/blood-2003-02-0649.

Peer) reviewing PDF | (2019:11:42851:1:3:NEW 25 Feb 2020) 
358 Pedram A, Razandi M, Wallace DC, Levin ER. 2006. Functional estrogen receptors in the

359

360

361

362

363

364

365

366

367

368

369

370

371

372

373

374

375

376

377

378

379

380

381

382

383

384

385

386

387

388

389

390

391

392

393

394

395

396

397

mitochondria of breast cancer cells. Molecular biology of the cell 17:2125-2137. DOI: 10.1091/mbc.e05-11-1013.

Radde BN, Alizadeh-Rad N, Price SM, Schultz DJ, Klinge CM. 2016. Anacardic Acid, Salicylic Acid, and Oleic Acid Differentially Alter Cellular Bioenergetic Function in Breast Cancer Cells. Journal of cellular biochemistry 117:2521-2532. DOI: 10.1002/jcb. 25544. Rodriguez-Cuenca S, Cochemé HM, Logan A, Abakumova I, Prime TA, Rose C, VidalPuig A, Smith AC, Rubinsztein DC, Fearnley IM, Jones BA, Pope S, Heales SJR, Lam BYH, Neogi SG, McFarlane I, James AM, Smith RAJ, Murphy MP. 2010. Consequences of long-term oral administration of the mitochondria-targeted antioxidant MitoQ to wild-type mice. Free radical biology \& medicine 48:161-172. DOI: 10.1016/j.freeradbiomed.2009.10.039. Russo J, Russo IH. 2006. The role of estrogen in the initiation of breast cancer. The Journal of steroid biochemistry and molecular biology 102:89-96. DOI: 10.1016/j.jsbmb.2006.09.004.

Salisbury JP, Williams JC Jr. 2009. Docking study of triphenylphosphonium cations as estrogen receptor $\alpha$ modulators. Bioinformation 3:303.

Severin FF, Severina II, Antonenko YN, Rokitskaya TI, Cherepanov DA, Mokhova EN, Vyssokikh MY, Pustovidko AV, Markova OV, Yaguzhinsky LS, Korshunova GA, Sumbatyan NV, Skulachev MV, Skulachev VP. 2010. Penetrating cation/fatty acid anion pair as a mitochondria-targeted protonophore. Proceedings of the National Academy of Sciences of the United States of America 107:663-668. DOI: 10.1073/pnas.0910216107.

Silachev DN, Plotnikov EY, Zorova LD, Pevzner IB, Sumbatyan NV, Korshunova GA, Gulyaev MV, Pirogov YA, Skulachev VP, Zorov DB. 2015. Neuroprotective Effects of Mitochondria-Targeted Plastoquinone and Thymoquinone in a Rat Model of Brain Ischemia/Reperfusion Injury. Molecules 20:14487-14503. DOI: 10.3390/molecules200814487. Vollmer G. 2003. Endometrial cancer: experimental models useful for studies on molecular aspects of endometrial cancer and carcinogenesis. Endocrine-related cancer 10:23-42. Vorobjeva N, Prikhodko A, Galkin I, Pletjushkina O, Zinovkin R, Sud'ina G, Chernyak B, Pinegin B. 2017. Mitochondrial reactive oxygen species are involved in chemoattractant-induced oxidative burst and degranulation of human neutrophils in vitro. European journal of cell biology 96:254-265. DOI: 10.1016/j.ejcb.2017.03.003.

Yamaga R, Ikeda K, Horie-Inoue K, Ouchi Y, Suzuki Y, Inoue S. 2013. RNA sequencing of MCF-7 breast cancer cells identifies novel estrogen-responsive genes with functional estrogen receptor-binding sites in the vicinity of their transcription start sites. Hormones \& cancer 4:222232. DOI: $10.1007 / \mathrm{s} 12672-013-0140-3$.

Yasar P, Ayaz G, User SD, Güpür G, Muyan M. 2017. Molecular mechanism of estrogenestrogen receptor signaling. Reproductive medicine and biology 16:4-20. DOI: $10.1002 / \mathrm{rmb} 2.12006$.

Yurova MN, Zabezhinski MA, Piskunova TS, Tyndyk ML, Popovich IG, Anisimov VN. 2011. Effect of mitochondria-targeted antioxidant SkQ1 on aging, lifespan, and spontaneous carcinogenesis in three strains of mice. Advances in gerontology $=$ Uspekhi gerontologii /

Peer) reviewing PDF | (2019:11:42851:1:3:NEW 25 Feb 2020) 
398 Rossiiskaia akademiia nauk, Gerontologicheskoe obshchestvo 1:260. DOI:

399 10.1134/S2079057011030155.

400 Zhou J, Wang H, Shen R, Fang J, Yang Y, Dai W, Zhu Y, Zhou M. 2018. Mitochondrial-

401 targeted antioxidant MitoQ provides neuroprotection and reduces neuronal apoptosis in

402 experimental traumatic brain injury possibly via the Nrf2-ARE pathway. American journal of

403 translational research 10:1887-1899.

404 Zielonka J, Joseph J, Sikora A, Hardy M, Ouari O, Vasquez-Vivar J, Cheng G, Lopez M, 405 Kalyanaraman B. 2017. Mitochondria-Targeted Triphenylphosphonium-Based Compounds: 406 Syntheses, Mechanisms of Action, and Therapeutic and Diagnostic Applications. Chemical 407 reviews 117:10043-10120. DOI: 10.1021/acs.chemrev.7b00042.

408 Zinovkin RA, Romaschenko VP, Galkin II, Zakharova VV, Pletjushkina OY, Chernyak 409 BV, Popova EN. 2014. Role of mitochondrial reactive oxygen species in age-related 410 inflammatory activation of endothelium. Aging 6:661-674. DOI: 10.18632/aging.100685. 411 Zinovkin RA, Zamyatnin AA. 2019. Mitochondria-Targeted Drugs. Current molecular 412 pharmacology 12:202-214. DOI: 10.2174/1874467212666181127151059. 
Figure 1

Mitochondria-penetrating cations used in the present study.

(A) $C_{12}$ TPP. (B) SkQ1. (C) SkQR1.

A

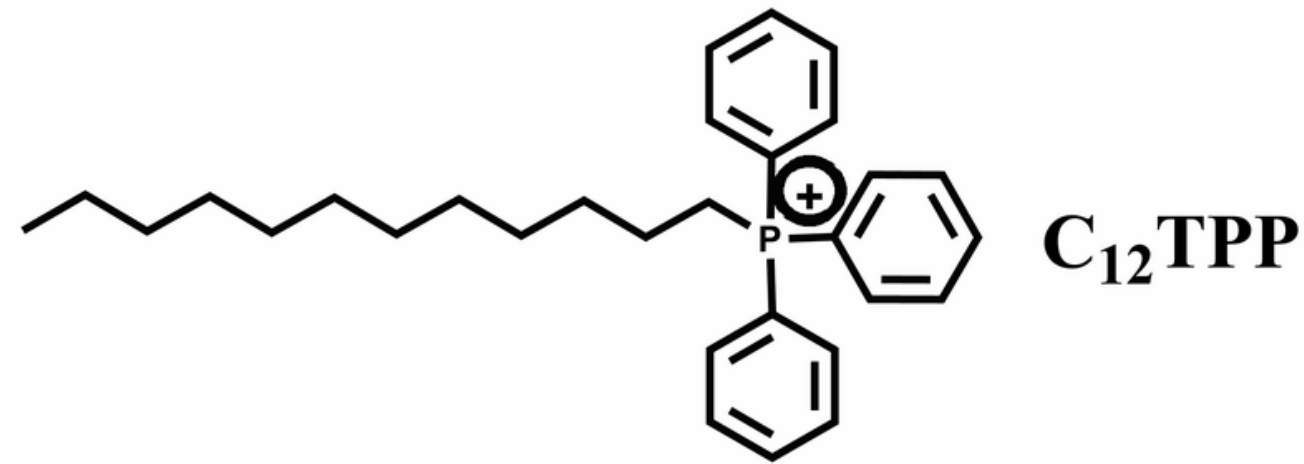

B<smiles>CC1=C(C)C(=O)C(CCCCCCCCCC[P+](c2ccccc2)(c2ccccc2)c2ccccc2)=CC1=O</smiles>

SkQ1<smiles>CCNc1cc2oc3cc(=O)c(C)cc-3c(-c3ccccc3C(=O)OCCCCCCCCCCCC3=CC(=O)C(C)=C(C)C3=O)c2cc1C</smiles> 


\section{Figure 2}

Effect of mitochondria-targeted compounds on the proliferation of ER-positive MCF-7 cells.

Cells (approximately 5,000 cells per well) were incubated for $48 \mathrm{~h}$ with (A) SkQ1; (B) $\mathrm{C}_{12}$ TPP;

(C) SkQR1, and DNP. Data are expressed as the percentage of the control cells $+/-$ standard deviation (SD), $n=5-6$. P values were determined using the one-way ANOVA with post-hoc Tukey HSD. *p, E2 compared with the control; \#p, E2 and E2 + fulvestrant.

A

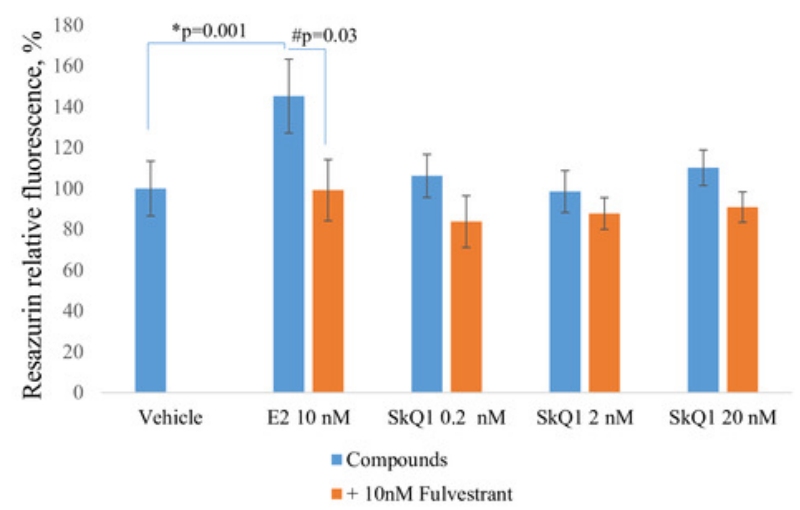

C

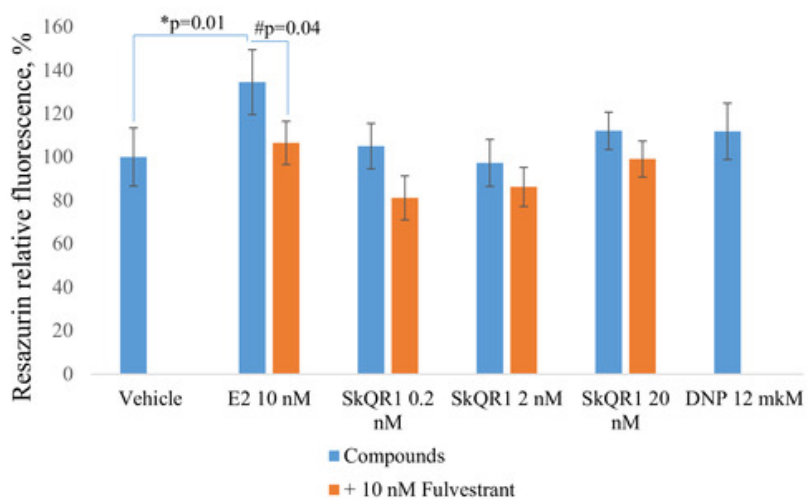

B

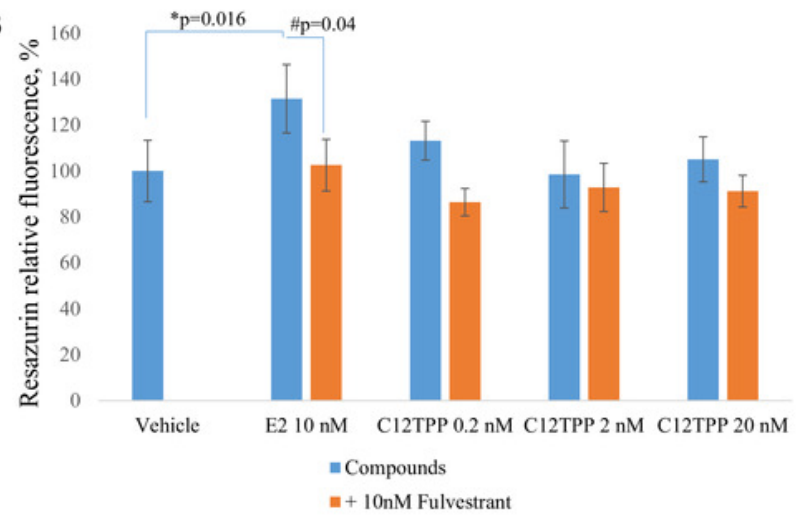


Figure 3

Effect of mitochondria-targeted compounds on the proliferation of ER-negative MDAMB-231 cells.

The cells were cultured and treated as shown in Fig. 2 and proliferation was analyzed using a resazurin assay. (A) SkQ1; (B) $C_{12}$ TPP; (C) SkQR1, and DNP. Data are expressed as a percentage of the control cell cultures $+/-S D, n=4$.

A

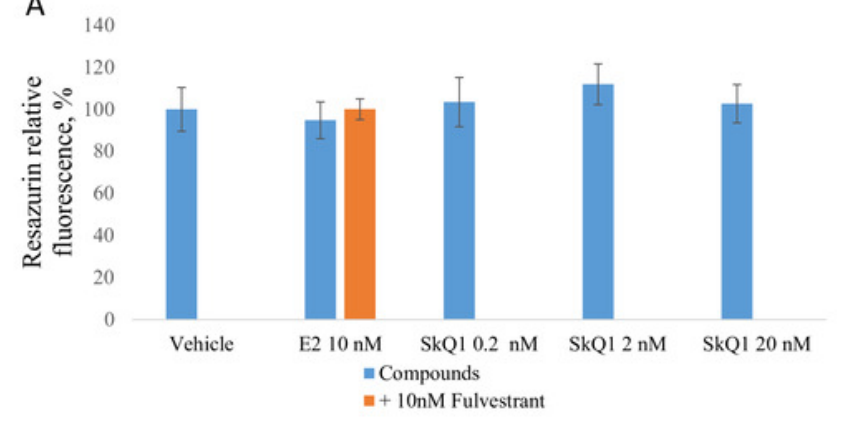

C

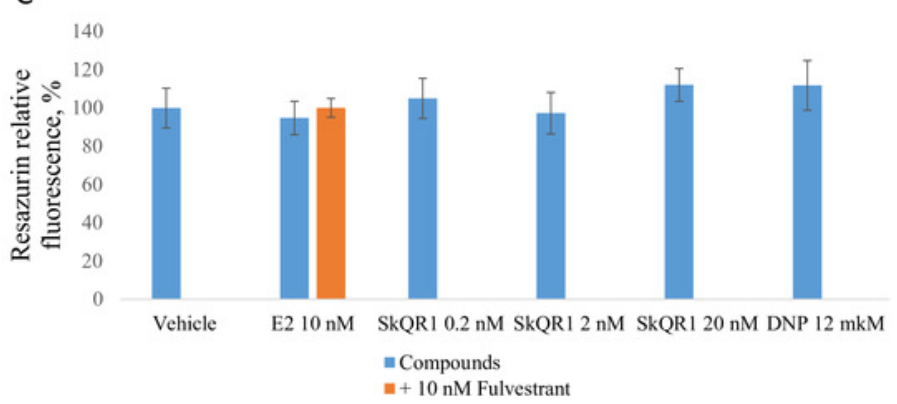

B

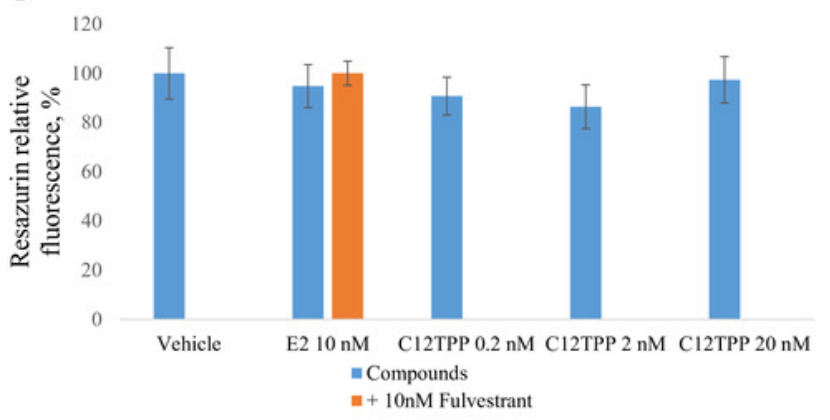


Figure 4

Proliferation of ER-positive MCF-7 cells treated with mitochondria-targeted compounds.

$\mathrm{Cl}$ values were dynamically monitored using a XCELLigence system after the administration (arrow) of 10 nM E2 (Estrogen), 20 nM SkQ1 (SkQ1), 20 nM C 12 TPP (C12TPP), or 20 nM SkQR1 (SkQR1). The average values of triplicate experiments are plotted against treatment time.

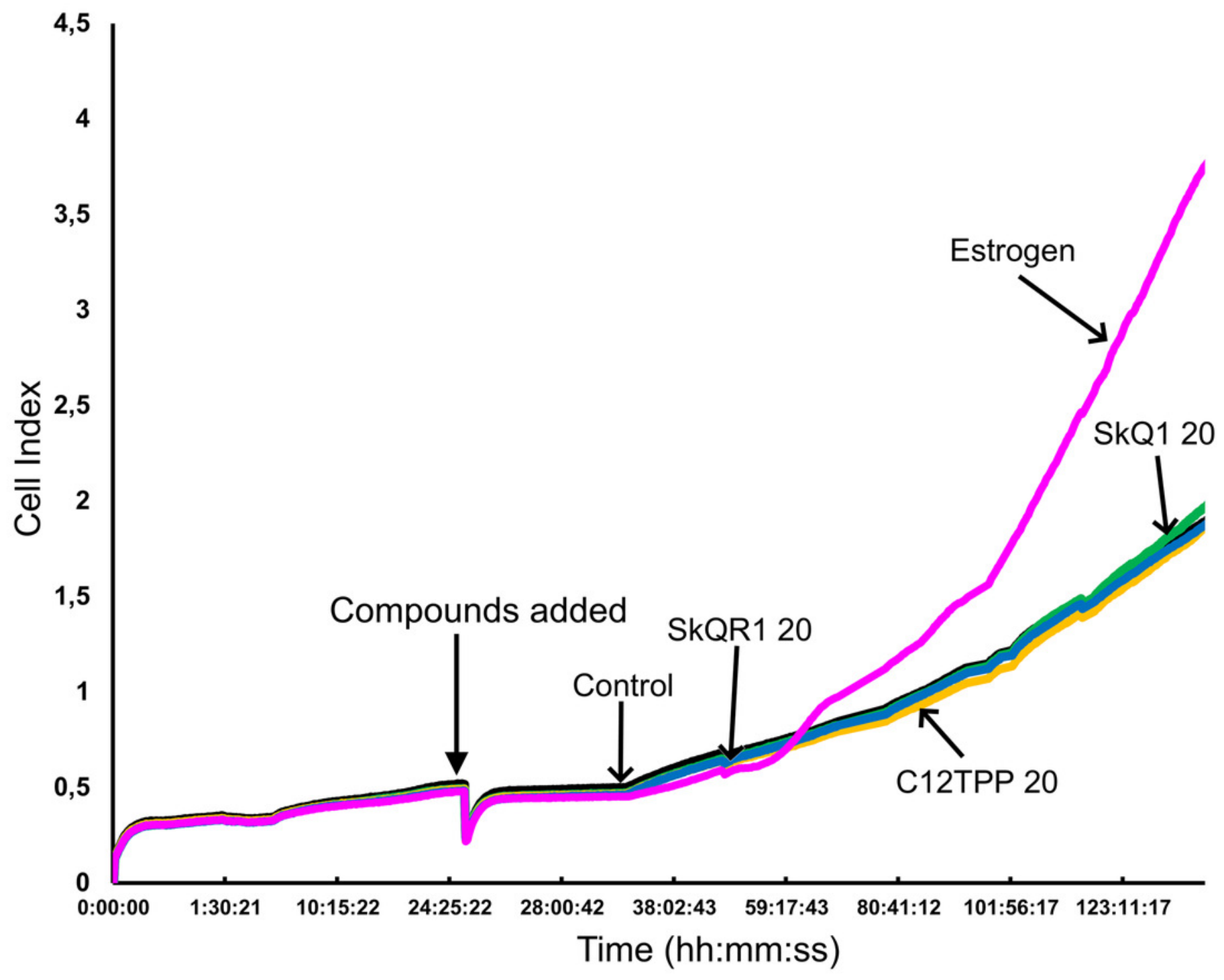


Figure 5

Cell cycle analysis of ER-positive MCF-7 cells.

Cells were treated as shown in Fig. 2. The cell cycle was analyzed using flow cytometry of PIstained cells. (A-E) Percentages of cells in S/G2/M phases. (A) "Control," untreated cells. (B) “Estrogen," 10 nM E2. (C) "SkQ1," 20 nM SkQ1. (D) “C12TPP," 20 nM C 12 TPP. (E) "SkQR1," 20 nM SkQR1. (F) Distributions of cells in G1/G0, S, and G2/M phases.
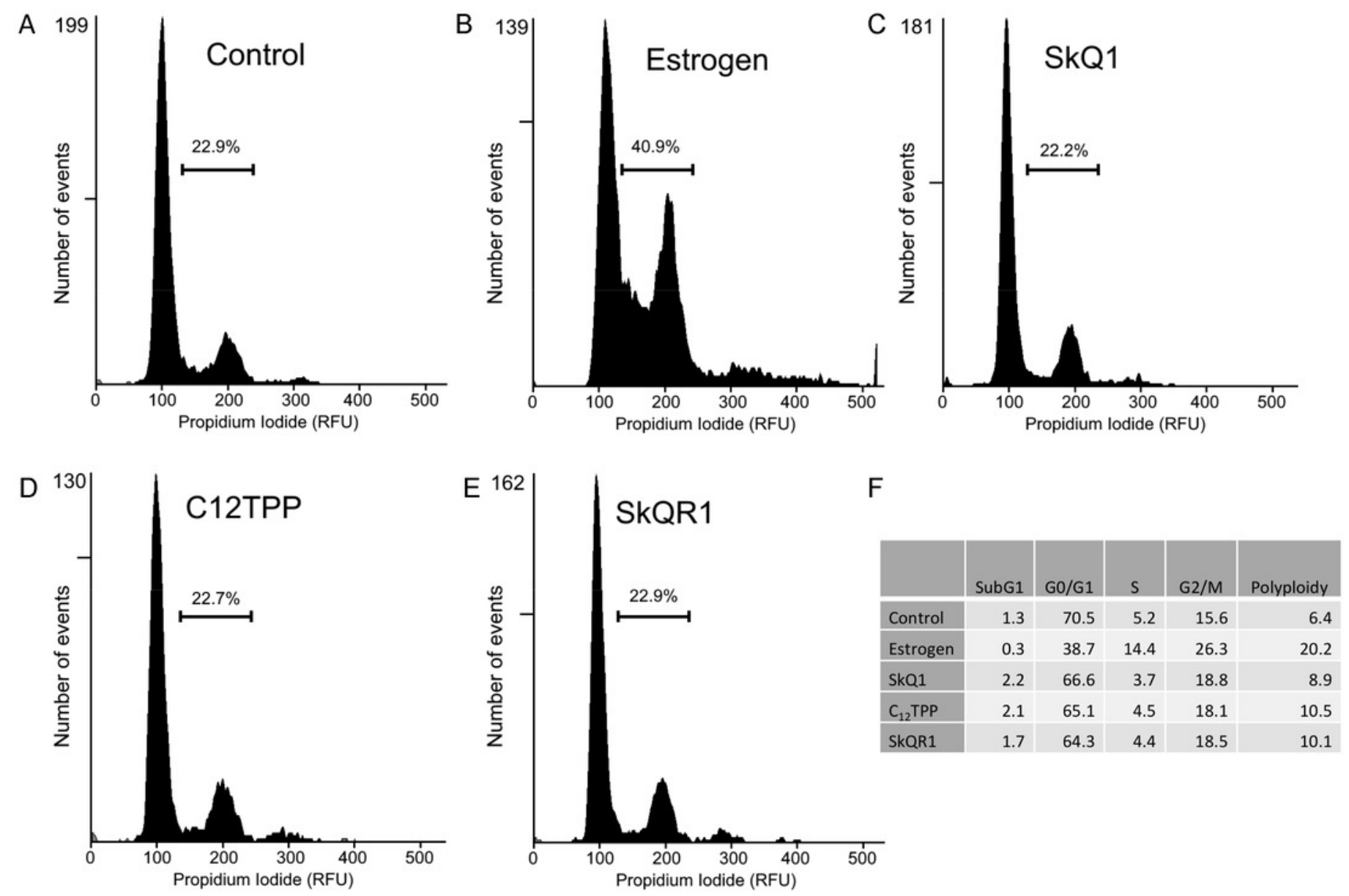


\section{Figure 6}

TPP-based compounds do not enhance expression driven by estrogen-responsive promoters in MCF-7 cells.

Cells were transfected with an $\mathrm{ERE}_{3}$-Luc reporter construct. Test compounds were added 24 $\mathrm{h}$ after transfection followed by measurement of luminescence $24 \mathrm{~h}$ later. Luminescence was normalized to the total protein content. Data are expressed as the percentage of untreated transfected cells $+/-S D, n=3 ; * p=0.04$, untreated control vs E2-treated cells; $\# p=0.04$, untreated vs cells treated with both E2 and fulvestrant (unpaired Student's $t$-test).

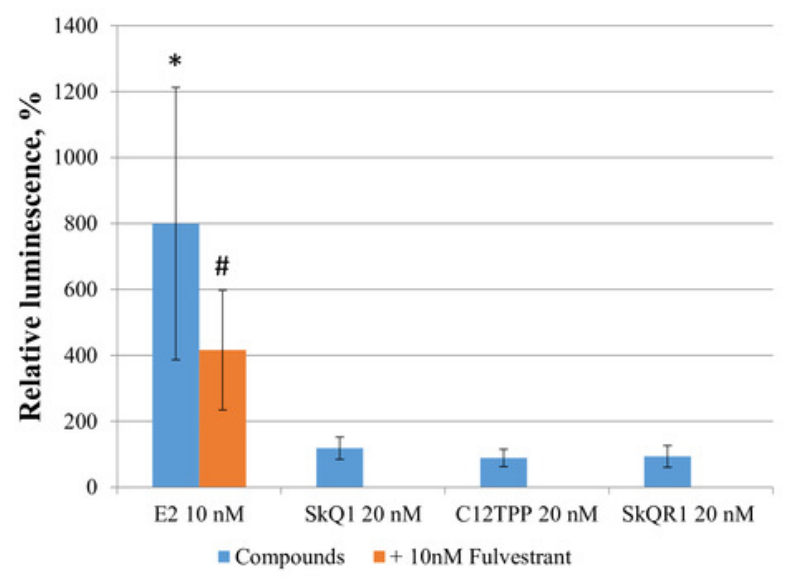




\section{Figure 7}

Analysis of gene expression in MCF-7 cells.

MCF-7 cells were treated as shown in Fig. 2, and the levels of mRNAs encoding GREB1, IGFBP4, COX6, and TFF1 were normalized to the reference RPL32 mRNA. The relative expression of the target genes in the untreated control cells is expressed as $100 \%$. The values represent the mean $+/-S D, n=4$. P-values were calculated using the unpaired Student's t-test; \#p, fulvestrant (Fulv) vs corresponding sample without fulvestrant; ${ }^{*} p$, samples without fulvestrant vs control.

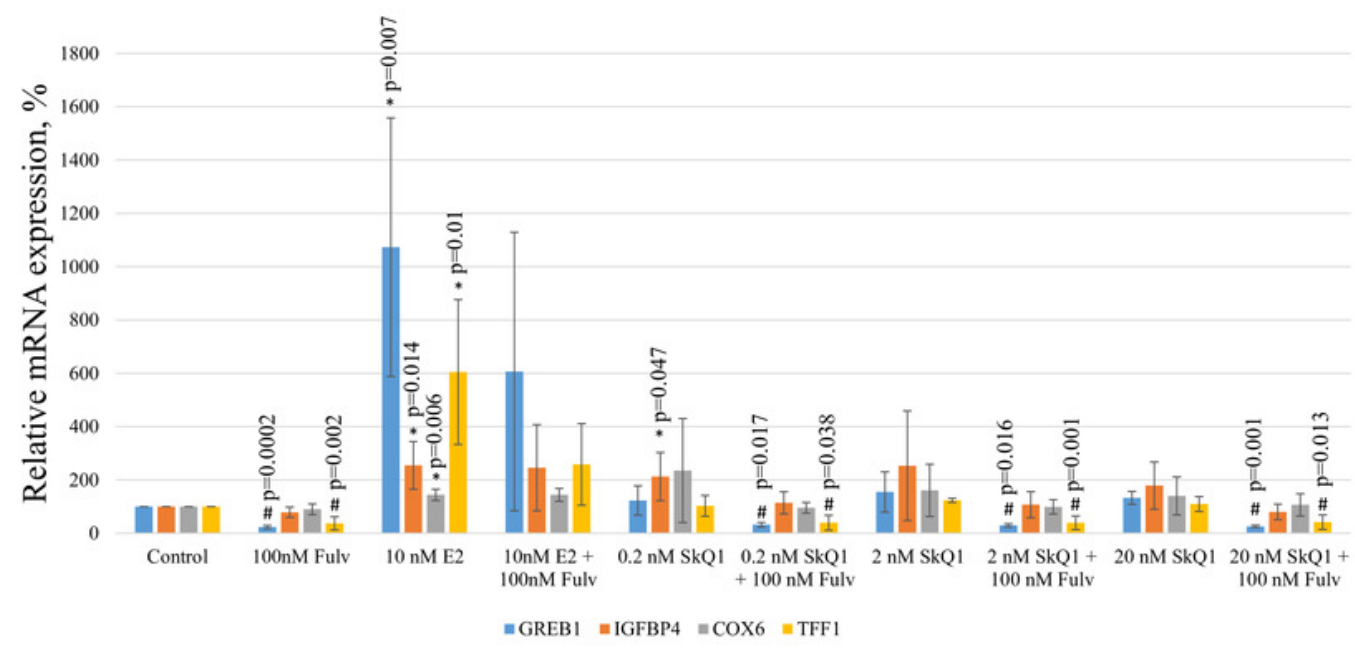

